\title{
Educação de jovens e adultos: um estudo acerca dos princípios políticos e pedagógicos que conduziram a proposta educacional do Movimento Brasileiro de Educação - MOBRAL (1967-1985)
}

Adult education: A study about the political and pedagogical principles that led to the educational proposal of the Brazilian Movement of Education - MOBRAL (1967-1985)

Educación de jóvenes y adultos: Um estúdio sobre lós principios políticos y pedagógicos que condujeron la propuesta educativa del Movimiento Brasileño de Alfabetización-MOBRAL

(1967-1985)

\author{
Mariana Lemos do Prado \\ Universidade Federal de Uberlândia (Brasil) \\ https://orcid.org/0000-0003-2326-5215 \\ http://lattes.cnpq.br/4238429433056788 \\ marianalis2003@yahoo.com.br \\ Armindo Quillici Neto \\ Universidade Federal de Uberlândia (Brasil) \\ https://orcid.org/0000-0003-2553-4693 \\ http://lattes.cnpq.br/6897277608755605 \\ armindo@ufu.br
}

\section{Resumo}

O Movimento Brasileiro de Educação - MOBRAL criado durante o Regime Militar (19641985), pela Lei $n^{\circ} 5.379$ de 15/12/1967, se constituiu em um dos mais extensos e complexos programas de educação de adultos já desenvolvidos no país. Para realização deste estudo foi elaborada uma análise dos princípios políticos, pedagógicos, metodologias e ideais que conduziram os principais programas do MOBRAL, com ênfase na Alfabetização Funcional, por meio da pesquisa bibliográfica e documental de fontes como: a documentação e legislação educacional do período (1967-1985); Estatutos e Documento Básico da Fundação; pesquisas acadêmicas; as publicações do MEC e os materiais didáticos do MOBRAL. Destacamos o trabalho de Arlindo Lopes Corrêa como idealizador, gestor e representante do MOBRAL, um intelectual que buscou mediar a unidade política e ideológica da instituição e legitimar seu trabalho perante a opinião pública.

Palavras chave: MOBRAL. Alfabetização Funcional. Princípios políticos e pedagógicos. 


\begin{abstract}
The Brazilian Literacy Movement (MOBRAL) created during the military regime (19641985) by the brazilian law $n^{\circ} 5.379$ of $15 / 12 / 1967$, was one of the most extensive and complex adult education program developed in the country. For this study, an elaborated analysis were made of the political and pedagogical principles, methodologies and ideals that led the main programs of MOBRAL, with emphasis on functional literacy, by means of bibliographical and documentary research of sources such as: documentation and educational legislation of the period (1967-1985); statutes and basic institutional documents; academic researches; publications of the Ministry of Education and the teaching materials for support of MOBRAL. We highlight the work of Arlindo Lopes Corrêa as founder, manager and representative of the MOBRAL, an intellectual who sought to mediate the political and ideological unity of the Movement and legitimize his work for the people.
\end{abstract}

Keywords: MOBRAL. Functional literacy. Political and pedagogical principles.

\title{
Resumen
}

El Movimiento Brasileño de Alfabetización- MOBRAL creado durante el régimen militar por la Ley n5.379 de 15/12/1967, se constituyó em uno de lós más extensos y complejos programas de aducación de adultos ya desarrollados em el país. Para la realización de este estúdio se elaboro uma análisis de los principios políticos, pedagógicos, metodologias e ideales que condujeron los principales programas Del MOBRAL, com énfasis en la Alfabetización funcional, a través de la investigación bibliográfica y documental de fuentes como: la documentación y legislación educativa del período(1967-1985); Estatutos y Documento Básico de la Fundación; investigaciones acadêmicas; las publicaciones del MEC y los materiales didáticos del MOBRAL. Destacamos el trabajo de Arlindo Lopes Corrêa como idealizador, gestor y representante del MOBRAL, um intelectual que buscó mediar la unidad política e ideológica de la instituición y legitimar su trabajo ante la opinión pública.

Palabras clave: MOBRAL. Alfabetización funcional. Principios políticos y pedagógicos. 


\section{Introdução}

A educação de jovens e adultos compreende um conjunto de múltiplos processos e práticas formais e informais, relacionados à formação básica e geral, e a aquisição de conhecimentos de ordem cultural, social, técnica e profissional, estendendo-se por quase todos os domínios da vida social. Sobre os sentidos atribuídos a esta modalidade de ensino Almeida e Corso (2015, p. 1284) esclarecem que,

A educação de jovens e adultos tem uma trajetória histórica de ações descontínuas, marcada por uma diversidade de programas, muitas vezes não caracterizada como escolarização. Com a aprovação da LDB 9394/96, a EJA é caracterizada como modalidade de educação básica correspondente ao atendimento de jovens e adultos que não freqüentaram ou não concluíram a educação básica. Esses documentos trouxeram alterações e ampliações conceituais produzidas desde o final da década de 1980, ao usar o termo Educação de Jovens e Adultos parra assinalar as ações anteriormente conhecidas como Ensino Supletivo.

O presente trabalho se propõe a realizar uma análise dos princípios políticos, pedagógicos, metodologias e ideais presentes no Movimento Brasileiro de Educação MOBRAL criado durante o Regime Militar (1964-1985), pela Lei ${ }^{\circ} 5.379$ de 15/12/1967. Entretanto somente em 1970, com seu desligamento do Departamento Nacional de EducaçãoDNE e transformação de sua proposta inicial, o MOBRAL passou a ser um órgão executor de programas de alfabetização e educação continuada para jovens e adultos. Neste período educação destinada a jovens e adultos analfabetos foi caracterizada pela expansão quantitativa, que resultou num processo de massificação, sem preocupação com as estruturas adequadas para garantir a qualidade, já que a meta prioritária era erradicar o analfabetismo no país em dez anos de atuação do programa.

Considerado "obra e braço da ditadura militar" Ferraro (2013, p. 76), o MOBRAL se constituiu em um dos mais extensos e complexos programas de educação de adultos já desenvolvidos no país. Autores como Oliveira (1989) e Souza (2016) apontam o MOBRAL como um importante instrumento para legitimação do regime, para o afastamento de ameaças esquerdistas que permeavam a educação popular, e para a construção de um ideal de democracia agenciado pelo regime ditatorial ${ }^{1}$ dos anos de 1964 a 1985 . Reflexo do contexto político, econômico e social de sua época, o MOBRAL foi sendo reestruturado com vistas à diversificação de suas atividades numa tentativa de justificar sua existência e garantir a continuidade de seus programas.

Porém, as reformulações do movimento, a ampliação de seu campo de atuação, e toda estrutura organizacional montada de forma a atuar em todos os municípios brasileiros, não foram suficientes para a consecução de sua meta inicial e prioritária: erradicar o analfabetismo até 1980. Dados do Censo Demográfico do IBGE mostram que na década de 1970 o país apresentava, entre a população brasileira acima de 15 anos de idade, uma taxa de analfabetismo de 33,6\%. Na década de 1980, após dez anos de atuação do MOBRAL, essa taxa se encontrava em 25,4\% (redução de apenas 8,2\%), um índice muito distante das expectativas iniciais de seus organizadores, que previam uma taxa de analfabetismo abaixo

\footnotetext{
1 Autores como Galvão (2014), Germano (2011) e Souza (2016) utilizam o termo "civil-militar" ou "empresarial militar" para caracterizar o regime ditatorial instaurado em $1^{\circ}$ de abril de 1964 , em virtude do amplo apoio de diversos setores da sociedade civil: Igreja Católica, classe média, Ordem dos Advogados do Brasil-OAB, grupos empresariais, empresas multinacionais e a imprensa.
} 
dos 10\% para o início da década de 1980. Em 06 de fevereiro de 1985, pelo Decreto n. 92.374 foi criada a Fundação EDUCAR para substituir o MOBRAL, extinto na mesma ocasião.

\section{MOBRAL: sua institucionalização e o lançamento dos programas de educação de massas}

O Golpe de 1964 depôs o então presidente João Goulart, instaurando um regime ditatorial, que se estendeu de 1964 a 1985. De acordo com Spigolon (2014, p.89) "o movimento político-militar de abril de 1964 representa de um lado, um golpe contra as reformas sociais que eram defendidas por setores progressistas da sociedade brasileira e, de outro, um golpe contra a incipiente democracia política nascida em 1945".

Resultado de uma coalizão militar e civil, o golpe representou a ascensão de um novo grupo no poder, envolvendo a articulação entre o conjunto das classes dominantes, ou seja, a burguesia industrial e financeira (nacional e internacional), o capital mercantil, latifundiários e militares, bem como um grupo de intelectuais e tecnocratas ligados ao Instituto de Pesquisas e Estudos Sociais - IPES. O IPES foi criado oficialmente em 1961 por um grupo de empresários, banqueiros e técnicos do Rio de Janeiro e de São Paulo, também conhecidos por "tecnocratas". Este grupo correspondia à principal entidade representativa burguesa, ao lado dos militares e alguns setores conservadores da Igreja Católica, a agir contra o governo nacional-reformista de João Goulart (GERMANO, 2011). Entre os colaboradores do IPES estavam Mário Henrique Simonsen e Arlindo Lopes Corrêa, principais organizadores do MOBRAL em 1967.

Analisando a atuação do Estado Militar, em matéria de educação no Brasil, Germano (2011) identificou em linhas gerais, os principais eixos, em torno dos quais, foi desenvolvida a política educacional:

1) Controle político e ideológico da educação escolar, em todos níveis. Tal controle, no entanto, não ocorre de forma linear, porém, é estabelecido conforme a correlação de forças existentes nas diferentes conjunturas históricas da época. [...] 2) Estabelecimento de uma relação direta e imediata, segundo a "teoria do capital humano", entre educação e produção capitalista [...] 3) Incentivo à pesquisa vinculada à acumulação de capital. 4) Descomprometimento com o financiamento da educação pública e gratuita, negando, na prática, o discurso de valorização da educação escolar e concorrendo decisivamente para a corrupção e privatização do ensino, transformado em negócio rendoso e subsidiado pelo Estado. (GERMANO, 2011, p.105-106).

Neste contexto, o governo buscou instituir uma educação de massas, como instrumento para a manutenção do poder político, e a legitimação das estruturas de dominação econômico-sociais vigentes. Neste sentido, Gramsci (2001) reconhece a educação das massas como um importante mecanismo de construção da consciência coletiva e individual, e critica sua utilização como instrumento de dominação e controle, com o qual o Estado busca manter sua hegemonia e conquistar o consentimento ativo daqueles sobre os quais governa. Nesta perspectiva de dominação, o governo militar, lança em 1967 o MOBRAL- Movimento Brasileiro de Alfabetização.

No dia 8 de setembro de 1967, na ocasião da comemoração do Dia Internacional da Alfabetização instituído pela UNESCO, o ministro da Educação e Cultura Tarso Dutra, juntamente com o presidente da República Marechal Costa e Silva assinaram diversos decretos prevendo: a constituição de um Grupo Interministerial - GI para estudo e levantamento de recursos destinados à alfabetização (Decreto 61.311); a utilização das 
emissoras de televisão nos programas de alfabetização (Decreto 61.312); a constituição da Rede Nacional de Alfabetização Funcional e Educação Continuada de Adultos (Decreto 61.313); e a implantação da Educação Cívica nas instituições sindicais e uma campanha em prol da extinção do analfabetismo (Decreto 61.314).

Após o encerramento das atividades do GI, foi instituído pela Lei 5.379 de 15 de dezembro de 1967, nos termos do Artigo 4º , o Movimento Brasileiro de Alfabetização - MOBRAL:

Art. 4. $^{\circ}$ - Fica o Poder executivo autorizado a instituir uma Fundação, sob a denominação de Movimento Brasileiro de Alfabetização MOBRAL, de duração indeterminada, com sede e foro na cidade do Rio de Janeiro, Estado da Guanabara, enquanto não for possível a transferência da sede e foro para Brasília. (MEC, 1973, p.50).

Pela Portaria Ministerial no 28 de 18 de janeiro de 1968 foi designada uma comissão especial encarregada da elaboração dos Estatutos do MOBRAL, que foram aprovados pelo Decreto 62.484, de 29/03/1968. Os estatutos definiram, em linhas gerais, as finalidades, a autonomia, o patrimônio, a organização e atribuições dos diferentes órgãos administrativos: a Presidência, o Conselho Administrativo e o Conselho de Curadores.

Apesar da rápida definição dos estatutos, organograma e toda estrutura administrativa, o MOBRAL ficou a espera de recursos financeiros necessários à execução de seu plano de ação. Estes recursos só foram obtidos posteriormente, pelo Decreto $\mathrm{n}^{\circ} 66.118$, de fevereiro de 1970 que concedia vinculação de parte da receita da Loteria Esportiva aos programas de alfabetização de adultos supervisionados pelo MEC; e pelo Decreto $\mathrm{n}^{\mathrm{o}} 1.124$ de setembro de 1970, que permitiu às pessoas jurídicas a doação de $1 \%$ do imposto de renda devido à Fundação MOBRAL.

A reestruturação do MOBRAL ${ }^{2}$ aconteceu em 1970, perante as divergências internas, entre o pessoal do DNE e o ministro da Educação Jarbas Passarinho, que demonstrava o interesse em realizar um projeto de alfabetização de adultos, que envolvesse a iniciativa privada e integrantes do Ministério do Planejamento e do Ipea. No dia 3 de junho foram nomeados para Secretaria Executiva (SEXEC) o Pe. Felipe Spotorno, e para presidência do MOBRAL, com mandato de 3 anos, o economista Prof. Mário Henrique Simonsen, que adotaram uma nova política de ação. Conforme Souza (2016, p. 59)

A chegada de Simonsen ao MOBRAL demonstrava uma tendência cada vez mais crescente no governo militar - a tecnocracia. Discípulo do Ministro Roberto Campos, Simonsen projetou as metas do MOBRAL e sua receita de forma compatível com os interesses econômicos em jogo, prometendo, em relativo curto espaço de tempo, desenvolver "uma ação extensiva alfabetizadora" que acabaria com o analfabetismo no Brasil até 1980.

O dia 8 de setembro de 1970 foi considerado o dia oficial do lançamento da nova fase do MOBRAL, que deixou de ser um órgão repassador de recursos para tornar-se executor de seus próprios programas, se consolidando como uma organização autônoma e independente. Foram assinados os primeiros convênios entre a Fundação MOBRAL e suas Comissões

\footnotetext{
${ }^{2}$ Essa reestruturação se deu em um clima de ruptura entre o grupo que concebeu o MOBRAL no DNE e o grupo originário da Secretaria Geral que reformulou sua política de ação. Ruptura causada por conflitos manifestos no âmbito da instituição, que revelam a luta travada em outros setores da educação brasileira entre os "pedagogos" e os "tecnocratas" (OLIVEIRA, 1989).
} 
Municipais recém-formadas em todos os municípios que faziam parte do Plano de Ação do Ministério do Interior. Garantidos os recursos financeiros, a nova direção traçou as linhas gerais da orientação que permitiu a instalação do MOBRAL em seus níveis nacional, estadual e municipal, e o lançamento de um amplo programa de alfabetização de massas, que se propunha a erradicar o analfabetismo até o final da década de 1980, além de implantar toda uma infraestrutura que lhe permitisse oferecer ação continuada à adolescentes e adultos.

De acordo com seus objetivos iniciais: a erradicação do analfabetismo e a educação continuada, o MOBRAL desenvolveu dois programas básicos: o Programa de Alfabetização Funcional - PAF e o Programa de Educação Integrada - PEI. Ao longo de sua atuação foram lançados outros programas: MOBRAL Cultural, o Programa de Desenvolvimento ComunitárioPDC, o Programa de Autodidatismo e o Programa de Profissionalização, que em seu conjunto formaram o Sistema de Educação Permanente. A partir de 1975 com a diversificação do movimento e a reestruturação do PDC, foram criados o Programa de Educação Comunitária para a Saúde (PES), o Programa Diversificado de Ação Comunitária (PRODAC).

\section{Arlindo Lopes Corrêa: o intelectual do MOBRAL}

De acordo com Haddad e Di Pierro (2000, p. 116), o engenheiro e economista Arlindo Lopes Corrêa assumiu a presidência do MOBRAL em 1974, "com a responsabilidade de defender o programa e assegurar sua continuidade, formulando justificativas técnicas em resposta à avalanche de críticas que recaíam sobre o órgão ${ }^{3 \%}$.

Entre estas justificativas, Corrêa (1979, p.46), ressalta a função democratizante da educação permanente, uma vez que esta deveria "atender primordialmente às parcelas mais carentes da população, incapazes, geralmente, por seus próprios meios, de construir seu crescimento educacional e, desse modo, impossibilitadas de ascensão social, política e econômica".

Em 1979 o MOBRAL lançou o livro "Educação de massa e ação comunitária", composto por dezenove capítulos escritos por diversos autores ligados ao MOBRAL, técnicos e ocupantes de altos cargos das principais gerências do MOBRAL Central, e de seus sistemas de planejamento e supervisão. Em seu conjunto a obra "se dedica a narrar os feitos do MOBRAL com o objetivo de explicar sua criação, justificar suas ações, estrutura e funcionalidade e principalmente defender-se das acusações." (SOUZA, 2016, p.184).

Os textos de apresentação: "MOBRAL - Pedagogia dos Homens Livres", e de fechamento: "O Futuro do MOBRAL", foram assinados por Arlindo Lopes Corrêa. Neles o autor declara sua intenção:

deixar consignada a experiência do MOBRAL para os pósteros. Não procuramos os aplausos do presente, mas estamos seguros de que o futuro reconhecerá o imenso valor de nossa obra, tão revolucionária que não poderia deixar de suscitar a dúvida, é certo, pois assim tem sido em toda a história da Humanidade com as realizações congêneres. [...] E temos ambições, é claro, pois sabemos de nossa capacidade de servir e queremos fazer cada vez mais. Mas a fraude, essa só existe nas ideias, nas palavras e nos gestos dos que tentam inutilmente macular nosso estrondoso sucesso. (CORRÊA, 1979, p. 12-13).

\footnotetext{
${ }^{3}$ Ao final da década de 1970 se avolumaram as críticas e acusações vindas de diversas instituições como a Sociedade Brasileira para o Progresso da Ciência - SBPC, a Coordenação de Aperfeiçoamento de pessoal de Nível Superior - CAPES e o MEC. (SOUZA, 2016).
} 
De maneira pretensiosa e em forma de desabafo Corrêa $(1979$, p. 11) rebateu as críticas recebidas pelo órgão: "Mas evidenciado o sucesso, a crítica surgiu com ares avassaladores, pois não se faz nada bem, impunemente, pois lá está a incompetência a combater o herói, o ídolo, aquele que se destaca". Ele também fez uma analogia entre o MOBRAL e o surgimento da vida na Terra, em uma referência a Teoria da Evolução de Charles Darwin ${ }^{4}$. O então presidente do órgão não poupou adjetivos para defender a metodologia do MOBRAL, herdada inicialmente da área econômica, e enaltecer o trabalho da equipe dos economistas e membros do Ipea:

Embora o tratamento metodológico dado ao setor educacional tenha sido exclusivamente econômico, o trabalho foi rico em descobertas e, na abertura de novos caminhos, pelo ineditismo da abordagem, apesar da desatualização das estatísticas, da inexistência de estudos e pesquisas - algumas das heranças do estado caótico da administração educacional encontrado em 1964 - foi possível identificar desperdícios e decisões irracionais. [...] Ao mesmo tempo era preciso conquistar os meios intelectuais e a opinião pública para a Economia da Educação. [...] Nessa época, inúmeros nomes importantes da economia brasileira reforçavam nossas teses - principalmente Roberto Campos, Mario Simonsen e Delfim Neto -, dando-lhes suporte junto aos centros de poder e aos veículos de comunicação social. (CORRÊA, 1979, p. 18-19).

Assim como procurou exaltar o trabalho do MOBRAL e justificar a necessidade da continuidade de seus programas, Corrêa (1979) empenhou-se para criticar e desqualificar as iniciativas de educação de adultos dos movimentos de cultura popular da década de 1960 abordados no item 2.1.3, em especial o método Paulo Freire e a "educação liberadora" de sua "pedagogia dos oprimidos":

Quando ouvimos falar dos chavões do comunismo internacional, da sua chamada "educação liberadora", da sua "pedagogia dos oprimidos", ocorre-nos que tudo isso começa com a grande contradição de que o ser humano é chamado a figurar dentro de um esquema que tem um objetivo previamente determinado, sobre o qual esse homem não influirá de modo algum. Ou será que os dogmas marxistas são passíveis de crítica nos "Centros de Cultura" em que se faz a "pedagogia dos oprimidos"? Não há dúvida: trata-se, mesmo, de uma pedagogia dos oprimidos. Não poderia haver algo mais opressor... Ao contrário, no MOBRAL as pessoas discutem com toda liberdade, e sem qualquer dirigismo, as coisas do seu mundo, que é também o mundo do alfabetizador, recrutado ali, no ambiente em que moram seus alunos. [...] no curso da "pedagogia dos oprimidos" trata-se de palavras de cunho revolucionário que incitam à luta armada, ao ódio entre classes A "educação libertadora”, no Brasil, usava como alfabetizadores os alunos de ensino superior engajados em

\footnotetext{
4 “Com a vida iniciou-se a evolução biológica, partindo da primitiva bactéria anaeróbia até chegar as suas formas superiores. Assim foi, também, com o MOBRAL, cujas origens têm que ser buscadas em janeiro de 1965, quando Mario Henrique Simonsen levou o então Ministro Roberto Campos a sugestão de criar, no Escritório de Pesquisa Econômica Aplicada (EPEA, hoje Ipea), um Setor de Educação, encarregado de desencadear o processo de planejamento educacional do Brasil.” (CORRÊA, 1979, p 18).
} 
sua campanha de incitação à subversão. Não era um movimento de alfabetização, com tonalidade política radical: era uma campanha de politização radical, se subversão, que se aproveitava da alfabetização como seu caldo de cultura. [...] Como tantas outras coisas, o prestígio da "educação libertadora" é o resultado de uma campanha promocional intensa do comunismo internacional, apenas um instrumento da "máquina". [...] Nossa educação é verdadeiramente democrática: mostramos a verdade e as pessoas fazem livremente as suas opções. À "pedagogia dos oprimidos" preferimos a "pedagogia dos homens livres". (CORRÊA, 1979, p.50-51, grifo nosso).

O posicionamento de Corrêa (1979) refletia o contexto social e político do governo militar: a oposição aos movimentos sociais e de educação popular da década de 1960, considerados subversivos e apontados equivocadamente como frutos do marxismo e do comunismo internacional ${ }^{5}$. O discurso do presidente da instituição também revela a contradição da proposta educacional do MOBRAL, ao proclamar uma educação "verdadeiramente democrática", onde os alunos "discutem com toda liberdade e sem qualquer dirigismo", em um país que vivia sobre o jugo da censura e do autoritarismo da ditadura militar ${ }^{6}$.

Ainda confrontando a "pedagogia dos oprimidos", Corrêa $(1979$, p.51) alegou que, o MOBRAL atendeu "milhões de alunos e não uns poucos como na pedagogia dos oprimidos". Como se fosse equivalente e justo comparar o número de alunos atendidos por um programa nacional de educação de massas, com comissões atuantes em todos os municípios brasileiros e que recebeu vultosos recursos financeiros, como foi o MOBRAL, com iniciativas não oficiais, de curta duração e localizadas em poucas cidades das regiões Nordeste e Sudeste, como foram as experiências dos Movimentos de Cultura Popular - MCPs e dos Centros de Cultura Popular- CPCs que utilizaram o método do educador Paulo Freire.

Em postagens feitas por Arlindo Lopes Corrêa nos anos de 2009 e 2010 em seu blog pessoal na internet, o engenheiro e economista tratou de temas como: educação, emprego e renda, terceira idade, esporte, ação comunitária, economia da educação, demografia, responsabilidade social, planejamento, políticas públicas e projetos sociais. Entre as 59 postagens feitas, Corrêa (2009) escreveu sobre sua experiência profissional como membro do Ipea e do MOBRAL. Em relação a sua trajetória no MOBRAL, Corrêa faz vários elogios à instituição, ao trabalho da equipe de supervisão e seus colaboradores, aos artistas, autores e ex-alunos que apoiaram seus programas, e à sua gestão: "Em convênio com o Banco Nacional de Habitação (BNH), criamos o Balcão de Ideias, para apresentação, pela clientela do MOBRAL, de técnicas de construção destinadas a baratear a moradia popular. Há trinta anos... reafirmando o pioneirismo do MOBRAL." (CORRÊA, 3 de Nov de 2009).

\footnotetext{
${ }^{5}$ Saviani (2013, p. 332), sustenta que "apesar do comparecimento de grande número de autores marxistas, a concepção de fundo que preside toda tessitura de Pedagogia do oprimido permanece sendo a filosofia personalista na versão política do solidarismo cristão". O autor argumenta que em Paulo Freire "a educação surgia como um instrumento de crucial importância para promover a passagem da consciência popular do nível transitivo-ingênuo para o nível transitivo-crítico, evitando-se a sua queda na consciência fanática. É em vista desse objetivo que foi criado um método de alfabetização ativo, dialogal, crítico e criticizador. Esse método, no entanto, é apenas um aspecto de uma proposta pedagógica mais ampla enraizada na tradição mais autêntica do existencialismo cristão, em diálogo com algumas contribuições do marxismo." (SAVIANI, 2013, p. 335).

${ }^{6}$ O período entre 1964 e 1969, ano em que foi publicado o livro Educação de massa e ação comunitária, apresenta um progressivo endurecimento do regime militar, com a instauração dos Atos Institucionais: "os direitos individuais e coletivos foram assim praticamente liquidados; o Congresso Nacional foi fechado e despojado de suas funções essenciais e o Poder Judiciário impedido de julgar.” (GERMANO, 2011, p.67).
} 
Corrêa (2009) também retoma alguns conflitos do passado, buscando se defender das críticas que foram feitas ao órgão: "Em relação ao MOBRAL, então, as mentiras que andam por aí são tantas e tão bizarras e despudoradas que às vezes não sei se devo rir ou chorar. Mas de uma coisa estou certo: um dia a verdade prevalecerá... Não sei é se vou receber esses atrasados do INSS!" (CORRÊA, 26 de Nov de 2009).

Como secretário executivo de 1972 a 1974, e especialmente como presidente de 1974 até 1981, Arlindo Lopes Corrêa foi o grande idealizador, gestor, representante e defensor do MOBRAL, à medida que seu discurso buscou mediar à unidade política e ideológica da instituição, e legitimar seu trabalho perante a opinião pública nacional e internacional. De acordo com Gramsci (198-, p.07):

Cada grupo social, nascendo no terreno originário de uma função essencial no mundo da produção econômica, cria para si, ao mesmo tempo e de um modo orgânico, uma ou mais camadas de intelectuais que lhe dão homogeneidade e consciência da própria função, não apenas no campo econômico, mas também no social e no político: o empresário capitalista cria consigo o técnico da industrial, o cientista da economia política, o organizador de uma nova cultura, de um novo direito, etc.

$\mathrm{O}$ autor esclarece que os intelectuais ${ }^{7}$ são os funcionários que exercem as funções organizativas e conectivas de uma classe dominante tentando manter sua hegemonia: "Os intelectuais são os 'comissários' do grupo dominante para o exercício das funções subalternas da hegemonia social e do governo político.” (GRAMSCI, 198-, p.14). Este grupo de intelectuais são representados no MOBRAL pelo já mencionado presidente da instituição e pelos ocupantes dos mais altos cargos das Gerências do MOBRAL Central, responsáveis pela elaboração e definição dos princípios metodológicos e das linhas de ação do órgão, com a finalidade de assegurar o consenso entre as massas e o grupo dirigente, desempenhado assim um papel essencial para a direção ideológica e política da hegemonia existente.

\section{Análise dos objetivos, metodologias e material didático do MOBRAL}

Dentre os diversos programas lançados pelo MOBRAL o Programa de Alfabetização Funcional- PAF se constituiu no programa central e básico do MOBRAL, que atendeu o maior número de pessoas e consumiu maior parte dos seus recursos. A alfabetização funcional preconizada pelo MOBRAL é "aquela que propicia à adolescentes e adultos a aplicação prática e imediata das técnicas de ler, escrever e contar, permitindo-lhes melhores condições de vida.” (MOBRAL, 1975, p.41). De acordo com o Documento Básico do MOBRAL:

A Alfabetização Funcional, que é o primeiro passo para que se atinjam os objetivos do MOBRAL, procura levar a pessoa humana:

- à aquisição de um vocabulário que permita um aumento de conhecimentos, à compreensão de orientações e ordens transmitidas por escrito e oralmente, à expressão clara de ideias e à comunicação escrita ou oral;

- ao desenvolvimento do raciocínio;

- à criação de hábitos de trabalho;

\footnotetext{
${ }^{7}$ A pesquisa de Gramsci sobre os intelectuais era motivada por sua preocupação com a classe proletária, e seu interesse em criar grupos de intelectuais de novo tipo, "que surjam diretamente da massa e que permaneçam em contato com ela para tornarem-se os seus sustentáculos.” (GRAMSCI, 1981, p. 27).
} 
- ao desenvolvimento da criatividade, visando entre outros, ao aproveitamento de todos os recursos disponíveis a fim de melhorar as condições de vida;

\section{- ao conhecimento de seus direitos e deveres;}

- ao empenho na conservação da saúde, na melhoria das condições de higiene pessoal, da família e da comunidade;

- à compreensão da responsabilidade de cada um na manutenção e melhoria das condições de limpeza e dos bens e serviços públicos da comunidade;

- à descoberta das formas de vida e bem-estar social dos grupos que participam do Desenvolvimento, à motivação para ser CONSTRUTOR E BENEFICÍARIO desse desenvolvimento. (MOBRAL, 1975, p. 41-42, grifo nosso).

Analisando os objetivos que constam no projeto político do MOBRAL, Mendonça (1985, p.87) compreende que "apenas a garantia de participação do mobralense no processo político é um objetivo viável e verificável: o mobralense, ao conseguir assinar o seu nome, perde sua condição de analfabeto e adquire o direito de votar e ser votado."

Os objetivos da alfabetização funcional, ao enfatizarem a criação de hábitos de trabalho e a compreensão, por parte dos alfabetizandos, das ordens transmitidas por escrito e oralmente, revelam a tendência do MOBRAL de considerar a educação como um investimento em formação de mão de obra. Corroborando a vertente tecnicista e sua ideia de educação como pressuposto do desenvolvimento econômico.

Com vistas à consecução dos objetivos do PAF, o MOBRAL elegeu uma metodologia própria "que se caracteriza em dar ao adulto consciência de sua condição de Homem e de suas possibilidades para se realizar como Pessoa, orientando, portanto, numa perspectiva existencial." (MOBRAL, 1973a, p.14). Conforme o Documento Básico do MOBRAL:

O MOBRAL não elegeu, por antecipação, nenhum método específico de alfabetização. Foram adotados métodos conhecidos para, em função dos resultados iniciais obtidos, selecionar-se o que melhor pudesse atender às necessidades de um programa de massa, sendo flexível o suficiente para atender as particularidades de cada região e de cada grupo populacional envolvido. O método, portanto, é o ECLÉTICO, baseado na decomposição das PALAVRAS GERADORAS.

Estas se apoiam nas necessidades básicas do HOMEM, estando ligadas aos temas de sobrevivência, segurança, necessidades sociais, e auto-realização, o que garante um alto grau de interesse e de envolvimento dos alunos. (MOBRAL, 1795, p. 43).

Tratou-se de um método silábico fonético sistematizado a partir da decomposição das palavras geradoras ilustradas no cartaz gerador: "a palavra geradora é a que dá base ao estudo dos fonemas e a descoberta de novas palavras, devendo estar sempre relacionada ao cartaz gerador.” (MOBRAL, 1973b, p.56). O método silábico fonético partia da decomposição das partes (sílabas e fonemas) para o todo (palavra), ou seja, da síntese para a análise (ARAÚJO, 2006). Após reunir as letras em sílabas, passava-se ao conhecimento das "famílias silábicas", em seguida ensinava-se a ler a palavra formada, com a combinação de sílabas formavam-se novas palavras e por fim ensinava-se frases isoladas.

Analisando as características metodológicas do PAF observa-se a preocupação com a estruturação de esquemas de planejamento, atividades e técnicas de ensino padronizados, com 
vistas à eficiência e produtividade do programa, numa ação pedagógica pré-determinada a ser executada por voluntários que, em sua maioria, não possuíam formação para o magistério. Sobre este aspecto Gramsci (198-, p. 122) adverte que, o aluno somente participará de forma ativa na escola, se esta for ligada à vida: "Os novos programas, quanto mais afirmam e teorizam sobre a atividade do discente e sobre sua operosa colaboração com o trabalho do docente, tanto mais são elaborados como se o discente fosse uma mera passividade."

O material didático utilizado pelo MOBRAL foi produzido por grandes editoras: Abril, Vecchi, Primor, Bloch e LISA - Livros Irradiantes. Depois de aprovado ${ }^{8}$, o material era adquirido pelo MOBRAL Central, e distribuído para as COMUNs. Para reduzir os custos e favorecer o Subsistema Logístico, foi adotado um material único para todo o país. Segundo os organizadores do Sistema MOBRAL (1973a, p. 15), "tal material é analisado pela equipe técnica do MOBRAL/Central, que se preocupa em selecioná-lo de acordo com sua adequação à realidade do educando, de modo a levá-lo a integrar-se no seu grupo e na sociedade.". Porém, ao adotar um material único para todo país, o MOBRAL ignorou as especificidades regionais e as diferentes realidades vivenciadas pelos alunos.

Apesar de ser produzido por diferentes editoras, o material didático do PAF apresentou uma orientação metodológica e técnicas de trabalho padronizadas de acordo com os critérios adotados pelo MOBRAL, para aprovação e aquisição dos conjuntos didáticos. As palavras geradoras são inspiradas nas mesmas temáticas, assim como os conteúdos dos livros de leitura e dos livros de exercícios de linguagem e matemática 9 .

O conteúdo do material didático para a alfabetização funcional e a educação continuada foi baseado nas necessidades, consideradas pela equipe da Gerência PedagógicaGEPED como fundamentais ao homem: educação, saúde, habitação, trabalho, alimentação, lazer, entre outras; que deveriam conduzir a escolha das palavras geradoras que, em geral, pouco variavam entre as publicações das diferentes editoras conveniadas.

Aspectos considerados pelo MOBRAL como essenciais ao indivíduo e sua vida em comunidade: trabalho, hábitos de higiene, cumprimento das obrigações civis, participação comunitária, patriotismo, entre outros, foram atrelados ao conjunto didático e metodológico. Em suas ilustrações eram difundidos os valores, normas e preceitos que engendravam o pensamento militar brasileiro e sua ação política, como respeito às autoridades, ordem, hierarquia e disciplina, em frases como "O povo vive em ordem; O povo ajuda o país; Todos devem ajudar”. De acordo com Puglia (2004, p. 03-04):

Um dos pontos de extrema importância para o pensamento militar e que se liga não somente aos aspectos políticos e também aos sociais é com relação à concepção organicista da sociedade, o que implica que ela deve ser ordeira, avessa ao conflito ou confusão, ou seja, comprometida com a ordem. O sentimento organicista militar passa a atuar em vários campos, não apenas para manter a ordem e organizar os próprios aparatos militares, mas também se expande como forma de análise social.

\footnotetext{
${ }^{8}$ Além da avaliação do critério custo, a aprovação do material didático foi realizada mediante ao atendimento de critérios referentes às características gráficas e pedagógicas, consideradas como expressivas da qualidade do material didático básico do PAF. Todas estas características foram delimitadas na Publicação do MOBRAL: Orientação para elaboração e reforma do material didático da Alfabetização Funcional, produzida pela Assessoria de Avaliação e Publicações ASVAP/ MOBRAL, Rio de Janeiro 1976.

${ }_{9}^{9}$ Os conteúdos propostos nos Livros de Exercícios de Matemática abrangeram os seguintes assuntos: estudo dos números e suas operações, estudo das frações, estudo das medidas, e estudo de figuras geométricas.
} 
Convém ressaltarmos que esta "ordem" foi estabelecida mediante censura, Atos Institucionais, exílio e desaparecimento de opositores políticos, e cidadãos cujos ideais eram considerados subversivos.

O material didático buscava transmitir uma visão otimista, pacífica e fragmentada da realidade, na qual não havia espaço para conflitos, questionamentos e contradições. Aos alunos era difundida a ideia de que bastaria trabalhar, participar do programa de alfabetização funcional, manter hábitos de saúde e higiene, e cumprir suas obrigações civis que, consequentemente, o indivíduo teria melhores condições de vida, um "futuro garantido" tornando-se um beneficiário do progresso do país.

As instruções detalhadas das propostas de trabalho contidas nos roteiros e manuais de orientações aos alfabetizadores revelam também a preocupação, por parte dos integrantes do MOBRAL Central, com a utilização correta deste material e o direcionamento da prática docente. Não havia espaço para reflexão ou questionamento dos princípios metodológicos e do funcionamento do programa. Ao enfatizar as altas taxas de analfabetismo como o grande mal social e um empecilho ao desenvolvimento econômico, os organizadores do MOBRAL acabavam por atribuir aos adultos analfabetos a responsabilidade pelo atraso educacional do país. Nesta perspectiva o governo já estaria fazendo a sua parte oferecendo formação e qualificação profissional, o êxito do MOBRAL e o progresso do país dependeria da adesão dos analfabetos e da comunidade.

Por influência da UNESCO, no Brasil, o Censo Demográfico de 1950 considerou "como sabendo ler e escrever entende-se as pessoas capazes de ler e escrever um bilhete simples, em um idioma qualquer" (FERRARO, 2002, p.31). Porém, nos manuais do MOBRAL esta classificação ia além da definição censitária "saber ler e escrever", o analfabeto era encarado como um indivíduo que vivia em "um mundo limitado", e por sua ingenuidade, baixa autoestima e passividade seria facilmente persuadido e influenciável, desde que o docente tomasse as atitudes pré-determinadas no manual do professor. Estas orientações evidenciam as estratégias estabelecidas aos docentes, para o envolvimento e manipulação dos adultos analfabetos.

Os roteiros de orientação e manuais dos alfabetizadores definiam ainda, métodos, técnicas de trabalho e atividades, consideradas pela equipe do MOBRAL central como capazes de obter melhores resultados e maior aproveitamento dos alunos. Nestas publicações foram prescritas: metodologias padronizadas para o ensino da leitura, escrita e matemática; sugestões de como utilizar o material didático; os passos a serem seguidos para a exploração do cartaz e da palavra geradora; recomendações sobre a utilização dos livros de leitura continuada e materiais complementares; o que fazer nos primeiros dias de aula; orientações quanto à preparação das aulas e a elaboração do Plano de Aula; instruções sobre como acompanhar o desenvolvimento do aluno e avaliar a escrita, leitura e matemática. Até os momentos reservados para o debate e discussão em grupo, possuíam orientações de como ser encaminhados de modo a evitar desvios e conter possíveis conflitos. Não havia espaço para a inovação e intervenção por parte do alfabetizador, já que os manuais já possuíam a determinação dos conteúdos e lições a serem trabalhadas, a dinâmica das aulas e o contexto dos debates.

\section{Considerações finais}

Reconhecendo a educação das massas como um importante mecanismo de construção da consciência coletiva e individual, o governo utilizou o MOBRAL como instrumento para a manutenção do poder político; para a legitimação das estruturas de dominação econômicosociais vigentes; para a suavização das tensões sociais, e até mesmo a ocultação das relações conflitantes existentes. Enquanto legitimava o governo militar afastava a educação popular, 
pública e libertadora tendo em vista cooptar as populações excluídas e as classes trabalhadoras para a neutralidade política e participativa.

Com as mudanças ocorridas no cenário econômico, social e político do país no final da década de 1970 e início dos anos 1980, que apontavam para uma progressiva abertura política, e vendo crescer a oposição ao movimento dentro do próprio governo, entre os profissionais e tecnocratas da educação, membros do MEC e do Ipea ${ }^{10}$, o MOBRAL buscou, no estabelecimento do Sistema de Educação Permanente e diversificação de seus programas, justificar sua existência e a necessidade da continuidade e ampliação de seu campo de atuação.

Porém, as reformulações, a diversificação dos programas, e toda estrutura organizacional montada de forma a atuar em todos os municípios brasileiros, não foram suficientes para a consecução da meta inicial e prioritária do MOBRAL: erradicar o analfabetismo até 1980. Dados do Censo Demográfico do IBGE mostram que de 1970 a 1980, houve uma redução de apenas $8,2 \%$ na taxa de analfabetismo entre as pessoas de 15 anos ou mais de idade, justamente o público alvo do MOBRAL:

Tabela 1 - Taxa de analfabetismo entre brasileiros acima dos 15 anos (1950-1991) Abrangência: Brasil/ Unidade: Percentual

Taxa de Analfabetismo

\begin{tabular}{lc}
\hline Período & 15 anos ou mais \\
\hline 1950 & 50,6 \\
1960 & 39,7 \\
1970 & 33,6 \\
1980 & 25,4 \\
1991 & 20,1 \\
\hline
\end{tabular}

Fonte: IBGE, Censo demográfico. Disponível em: <http://seriesestatisticas.ibge.gov.br $>$

A estrutura administrativa e a complexidade de seus sistemas de supervisão, informação e logística evidenciam a centralização, hierarquização e rigidez no controle dos processos. Reflexo da tecnocracia que permeava a operacionalização do movimento, a influência do Ipea e do Ministério do Planejamento se afirma na escolha de Arlindo Lopes Corrêa para secretário executivo e presidente do MOBRAL. Corrêa se destaca como idealizador, gestor e representante do MOBRAL, um intelectual que buscou mediar a unidade política e ideológica da instituição e legitimar seu trabalho perante a opinião pública. Mesmo depois de três décadas da extinção do MOBRAL, Corrêa permaneceu firme em sua orientação tecnocrática e na defesa do movimento, considerado por ele um órgão pioneiro e inovador que conquistou feitos inéditos para a educação brasileira.

A ênfase na normatização dos procedimentos a serem seguidos reduziu o alfabetizador a mero executor de um programa previamente estabelecido. A ideia difundida nos roteiros e manuais de orientações ao professor era de que a metodologia mobralense foi tão bem estruturada e supervisionada que, juntamente com o material didático oferecido, seriam capazes de suprir as demais carências.

Os ideais de Nação, progresso, e democracia, contrastam com o contexto político e social da ditadura civil-militar instaurada, nas publicações do MOBRAL é veiculada a ideia de que o país vivia em ordem, e que o povo teria seus direitos contemplados e melhores condições de vida. Não havia espaço para questionamentos e conflitos, "ordem e progresso"

\footnotetext{
${ }^{10}$ Alguns membros do MEC e Ipea críticos ao MOBRAL pleiteavam o repasse de parte de suas verbas para o ensino fundamental, afirmando que os recursos técnicos e financeiros seriam mais bem empregados, se canalizados para os anos iniciais do ensino de primeiro grau.
} 
era a máxima disseminada pelos materiais didáticos. Suas lições, e campanhas publicitárias conciliavam a propaganda em prol do governo, com a exaltação ao MOBRAL e seus feitos.

Pela avaliação crítica da proposta educacional do MOBRAL, tendo em vista o contexto político, econômico e social de sua época, evidencia-se a contradição de um regime autoritário e excludente que proclamava a universalização e a democratização do ensino. Um dos principais reflexos desta contradição foi justamente o insucesso do MOBRAL em atingir seus objetivos.

\section{Referências}

ALMEIDA, A.; CORSO, A. M. A educação de jovens e adultos: aspectos históricos e sociais. In:XII CONGRESSO NACIONAL DE EDUCAÇÃO. Formação de professores, complexidade e trabalho docente. Pontifícia Universidade Católica do Paraná - PUC PR: Curitiba, 2015. p. 1283-1299. Disponível em: <http://educere.bruc.com.br/arquivo/ pdf2015/22753_10167.pdf>. Acesso em: 10 jan. 2017.

ARAÚJO, José Carlos Souza. Do quadro-negro à lousa virtual: técnica, tecnologia e tecnicismo. In: VEIGA, Ilma Passos Alencastro (Org.). Técnicas de ensino: novos tempos, novas configurações. Campinas: Papirus, 2006. p. 13-48.

BEISIEGEL, C. R. Estado e educação popular, Brasília: Líber Livro, 2004.

BRASIL. Ministério da Educação e Cultura. Lei $n^{o} 5.379$ de 15/12/1967. Prevê sobre a alfabetização funcional e a educação continuada de adolescentes e adultos. Brasília, DF: Fundação Movimento Brasileiro de Alfabetização. 1973a. Disponível em: $<$ http://www.dominiopublico.gov.br>. Acesso em: 14 ago. 2016.

. Ministério da Educação e Cultura. Decreto - lei $n^{\circ} 62.484$ de 23/03/1968. Aprova o Estatuto da Fundação Movimento Brasileiro de Alfabetização. Brasília, DF: Fundação Movimento Brasileiro de Alfabetização. 1973b. Disponível em: $<$ http://www.dominiopublico.gov.br>. Acesso em: 14 ago. 2016.

. Ministério da Educação e Cultura. Decreto - lei $n^{\circ} 594$ de 27/05/1969. Instituiu a Loteria esportiva federal e dá outras providências. Brasília, DF: Fundação Movimento Brasileiro de Alfabetização. 1973c. Disponível em: <http://www.dominiopublico.gov.br>. Acesso em: 14 ago. 2016.

. Ministério da Educação e Cultura. Documento básico de treinamento: Mobral. Rio de Janeiro, 1973d. 66p. Disponível em: <http://www.dominiopublico.gov.br $>$. Acesso em: 14 ago. 2016.

CORRÊA, Arlindo Lopes. Educação de Massa e Ação Comunitária. Rio de Janeiro: MOBRAL AGGS, 1979, 472p.

Educação, esporte, sustentabilidade. 03 nov. 2009. Disponível $\overline{\mathrm{em}:<\mathrm{h} t \mathrm{t}}$ ://www.arlindolopescorrea.blogspot.com.br>. Acesso em: 11 jul. 2015.

. INSS, Ipea, emprego, filme 2012, doping. 26 nov. 2009. Disponível

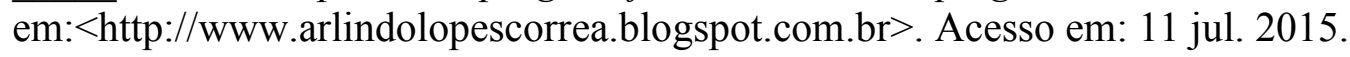


FÁVERO, O. ; MOTTA, E. (Org.). Educação de Jovens e Adultos. 1. ed. Petrópolis, RJ: De Petrus et Alii; Rio de Jeniro: FAPERJ, 2015. 1 DVD-ROM.

FERRARO, A. R. Analfabetismo e níveis de letramento no Brasil: o que dizem os censos? Revista Educação \& Sociedade, Campinas, vol. 23, n. 81, p. 21-47, dez. 2002. Disponível em: $<$ http://www.cedes.unicamp.br>. Acesso em: 01 jun. 2017.

FREIRE, Paulo. Pedagogia do oprimido. 62. ed. Rio de Janeiro: Paz e Terra, 2016.

GAVÃO. B. C. O papel do intelectual na construção do consenso durante a ditadura militar. 2014. Dissertação (Mestrado em Comunicação e Cultura) - Escola de Comunicação, Universidade Federal do Rio de Janeiro, Rio de Janeiro, 2014. Disponível em: $<$ http://http://www.pos.eco.ufrj.br.pdf>Acesso em: 17 jan. 2016.

GERMANO, José Willington. Estado Militar e Educação no Brasil (1964/1985). 5. ed. São Paulo: Cortez, 2011.

GRAMSCI, Antonio. Os intelectuais e a organização da cultura. Tradução de Carlos Nelson Coutinho. São Paulo: Círculo do Livro, [198-]. 220 p.

. Concepção dialética da história. Tradução de Carlos Nelson Coutinho. 4. ed. Rio de Janeiro: Civilização Brasileira, 1981. 341 p.

. Cadernos do cárcere, volume 2. Tradução de Carlos Nelson Coutinho. 2. ed. Rio de Janeiro: Civilização Brasileira, 2001.334 p.

HADDAD, Sérgio; DI PIERRO, Maria Clara. Escolarização de Jovens e adultos. Revista Brasileira de Educação, maio-ago. $\mathrm{n}^{\circ}$ 14, 2000. São Paulo. p.108-194.Disponível em: $<$ http://www.scielo.br>. Acesso em: 5 ago. 2015.

IBGE. Censo demográfico 1950-1991. Disponível em: <http://seriesestatisticas.ibge.gov.br>. Acesso em: 2 maio 2017.

MENDONÇA, T. N. J. Movimento brasileiro de alfabetização: subsídios para uma leitura crítica do discurso oficial. Goiânia: Ed. da Universidade Federal de Goiás, 1995. 186p.

MOBRAL. Sistema MOBRAL. Rio de Janeiro, 1973a. Disponível em: $<$ http://www.dominiopublico.gov.br>. Acesso em: 11 ago. 2016.

. Roteiro do Alfabetizador. Rio de Janeiro: Bloch, 1973b, 66 p.

. Documento Básico. Rio de Janeiro, 1975.86 p. Disponível em: $\overline{<\mathrm{http}: / /}$ www.dominiopublico.gov.br>. Acesso em: 14 ago. 2016.

OLIVEIRA, J. L. As origens do MOBRAL 1967/1970. 1989. 264 f. Dissertação (Mestrado em Educação) - Instituto de Estudos Avançados em Educação, Fundação Getúlio Vargas, Rio de Janeiro, 1989. Disponível em: http://bibliotecadigital.fgv.br/dspace/handle/10438/8912. Acesso em: 16 fev. 2016. 
PAIVA, Vanilda Pereira. História da educação popular no Brasil: educação popular e educação de adultos. 6. ed. São Paulo: Edições Loyola, 2003.

PUGLIA, D. B. Pensamento militar brasileiro e ação política. In: XVII Encontro Regional de História- O lugar da História. ANPUH/SP - UNICAMP. Campinas, 6 a 10 de setembro de 2004. CD-ROM.

SAVIANI, Dermeval. História das ideias pedagógicas no Brasil. 4. ed. Campinas, SP: Autores Associados, 2013.

SPIGOLON, Nima Imaculada. As noites da ditadura e os dias de utopia... O exílio, a educação e os percursos de Elza freire nos anos de 1964 a 1979. 2014. 506 f. Tese (Doutorado em Educação) - Faculdade de Educação, Universidade Estadual de Campinas, Campinas, 2014. 